\title{
Formação e prática pedagógica na Educação Física escolar: a percepção dos professores sobre a temática lutas
}

Training and pedagogical practice in school physical education: the perception of teachers on the theme of fights

Formación y práctica pedagógica en educación física escolar: la percepción de los docentes sobre el tema de las luchas

\author{
Mabel Dantas Noronha Cisne \\ ORCID: https://orcid.org/0000-0003-2371-1983 \\ Universidade Estadual do Ceará, Brasil \\ E-mail: mabeldantas12@gmail.com \\ Maria Petrília Rocha Fernandes \\ ORCID: https://orcid.org/0000-0001-9965-639X \\ Universidade Estadual do Ceará, Brasil \\ E-mail: petrilia@hotmail.com \\ Leandro Nascimento Borges \\ ORCID: https://orcid.org/0000-0001-8592-0436 \\ Universidade Estadual do Ceará, Brasil \\ E-mail: leandronborges@gmail.com \\ Mateus Lemos Barroso \\ ORCID: https://orcid.org/0000-0002-3307-1636 \\ Secretaria Estadual de Educação do Ceará, Brasil \\ E-mail: mateuslemosb@gmail.com \\ Pedro Henrique Silvestre Nogueira \\ ORCID: https://orcid.org/0000-0002-1533-9387 \\ Universidade Estadual do Ceará, Brasil \\ E-mail: pedrohenrique.livia91@gmail.com \\ Maria Iranilda Meneses Almeida \\ ORCID: https://orcid.org/0000-0002-0135-7189 \\ Universidade Estadual do Ceará, Brasil \\ E-mail: ma.iranildameneses@gmail.com \\ Maria Neurismar Araújo de Souza \\ ORCID: https://orcid.org/0000-0002-5260-7133 \\ Universidade Estadual do Ceará, Brasil \\ E-mail: neurismararaujodes@gmail.com \\ Luiza Lúlia Feitosa Simões \\ ORCID: https://orcid.org/0000-0002-2035-037X \\ Universidade Estadual do Ceará, Brasil \\ E-mail: luizalfsimoes@gmail.com \\ Heraldo Simões Ferreira \\ ORCID: https://orcid.org/0000-0003-1999-7982 \\ Universidade Estadual do Ceará, Brasil \\ E-mail: heraldo.simoes@uece.br
}

\begin{abstract}
Resumo
Este estudo teve como objetivo analisar a percepção dos professores de Educação Física escolar acerca da formação e prática pedagógica para aplicação da temática Lutas. O caminho metodológico caracterizou-se por uma investigação exploratória, cuja abordagem é quanti-qualitativa. Os participantes foram seis (06) professores de Educação Física da rede municipal de Fortaleza-Ceará. Os dados foram coletados por meio de um questionário on-line, através da Plataforma Google Forms e analisados usando a análise de conteúdo de Bardin (2011). Constatou-se nos resultados que apesar das mudanças propostas nas últimas décadas no que se refere ao entendimento sobre lutas na escola, ainda existe aproximação limitada dos participantes acerca da unidade temática lutas na formação inicial, devido a sua ausência nas matrizes curriculares ou por sua abordagem insuficiente. Esses dados contribuem para novas reflexões acerca da importância da Educação Física na formação e desenvolvimento de um cidadão crítico, autônomo e protagonista por meio de um trabalho planejado, inclusivo, democrático e integral, ampliando as possibilidades formativas, garantido o direito dos alunos de vivenciar, discutir e se apropriar das práticas corporais mais diversas. Portanto, propõe-se, que os professores que lecionam na educação básica busquem realizar leituras e estudos que
\end{abstract}


envolvam a inserção das lutas nas aulas de Educação Física escolar, tendo em vista atribuir um maior significado à essa manifestação cultural produzida e transformada com o desenvolvimento da humanidade.

Palavras-chave: Educação física; Escola; Formação; Lutas.

\begin{abstract}
This study was intended to analyze the perception of School Physical Education teachers about training and pedagogical practice for the application of the theme of Fights. The methodological path was characterized by an exploratory investigation, whose approach is quanti-qualitative. The participants were six (06) Physical Education teachers from the municipal network of Fortaleza-Ceará. Data were collected by means of an online questionnaire, through the Google Forms Platform and analyzed using Bardin's content analysis (2011). In the results, it was found that, despite the changes proposed in recent decades with regard to the understanding of fights at school, there is still limited approximation of the participants about the thematic unit of fights in initial training, due to its absence in the curriculum matrices or its insufficient approach. These data contribute to new reflections on the importance of Physical Education in the training and development of a critical, autonomous and protagonist citizen, through planned, inclusive, democratic and integral work, expanding training possibilities, guaranteeing the right of students to experience, discuss and take ownership of the most diverse bodily practices. Therefore, it is proposed that teachers who teach in primary education seek to carry out readings and studies that involve the insertion of fights in School Physical Education classes, with a view to assigning a greater meaning to this cultural manifestation produced and transformed with the development of mankind.
\end{abstract}

Keywords: Physical education; School; Training; Fights.

\title{
Resumen
}

Este estudio pretendió analizar la percepción de los docentes de Educación Física Escolar sobre la formación y la práctica pedagógica para la aplicación del tema de las luchas. El camino metodológico se caracterizó por una investigación exploratoria, cuyo enfoque es cuanti-cualitativo. Los participantes fueron seis (06) docentes de Educación Física de la red municipal de Fortaleza-Ceará. Los datos se recopilaron mediante un cuestionario en línea, a través de la Plataforma Google Forms y se analizaron utilizando el análisis de contenido de Bardin (2011). En los resultados, se encontró que, a pesar de los cambios propuestos en las últimas décadas en cuanto a la comprensión de las luchas en la escuela, aún existe una escasa aproximación de los participantes sobre la unidad temática de las luchas en la formación inicial, debido a su ausencia en las matrices curriculares o su enfoque insuficiente. Estos datos contribuyen a nuevas reflexiones sobre la importancia de la Educación Física en la formación y el desarrollo de un ciudadano crítico, autónomo y protagonista, a través del trabajo planificado, inclusivo, democrático e integral, ampliando las posibilidades de formación, garantizando el derecho de los estudiantes a experimentar, discutir y asumir la propiedad de las prácticas corporales más diversas. Por consiguiente, se propone que los docentes que imparten docencia en la educación primaria busquen realizar lecturas y estudios que impliquen la inserción de las luchas en las clases de Educación Física Escolar, con miras a otorgar mayor significado a esta manifestación cultural producida y transformada con el desarrollo de la humanidad.

Palabras clave: Educación física; Escuela; Formación; Luchas.

\section{Introdução}

As lutas são manifestações que fazem parte da cultura corporal de movimento. As práticas de lutas emergem como técnicas espetaculares para disciplinar, de forma categórica, embora sem inevitavelmente explicitar de que modo se compreende um sujeito disciplinado. Se considerarmos a apropriação e atenção aos valores que permeiam os princípios das relações humanas como experiência advinda do exercício das lutas, possivelmente teremos um cidadão capacitado e munido do aumento de suas habilidades físicas e espirituais.

Inúmeros autores realizam extensas pesquisas sobre os objetivos das lutas dentro do contexto escolar, reforçando que os objetivos da luta na escola possuem uma relação estreita com os objetivos da Educação Física Escolar. Entretanto, conforme apontam Rufino e Darido (2015), é necessário encontrar um caminho para solucionar as dificuldades e trabalhar as lutas no ambiente escolar, visto que este conteúdo exerce grande influência sobre a sociedade atual, aumentando nos últimos anos o número de praticantes, expectadores e consumidores referente às inúmeras manifestações que compõem o vasto leque do mundo das lutas.

Nesta perspectiva, Ferreira (2012) ao se referir sobre a abordagem das lutas nas aulas de Educação Física Escolar, parte expondo os inúmeros benefícios que envolvem essa prática, dentre os quais destaca o desenvolvimento motor, cognitivo 
e afetivo-social, além de sua presença ser justificada pelo fato de desenvolver nos estudantes, atitudes de respeito, cidadania, consciência e controle emocional que irão contribuir para uma formação global do educando, e não só unicamente com fins esportivos.

Para os autores, Rufino e Darido (2015) citando Mauri (2001), a construção do conhecimento é um movimento entrelaçado à cultura, devido a estrutura do seu processo de elaboração. Toda e qualquer atividade humana, é referenciada pela inclusão de linguagens e marcas com sentido cultural, o ato de lutar é um fenômeno inerente à sociedade. É preciso proporcionar aos alunos vivências relevantes, viabilizando a aprendizagem de valores que irão contribuir para a formação de um cidadão crítico. Sendo assim, reforçamos que as lutas são práticas historicamente fundamentais da cultura corporal de movimento dos seres humanos, e que devem ser ensinadas na escola, nas aulas de Educação Física.

Esse suporte se faz necessário por termos conhecimentos de algumas dificuldades e empecilhos para as lutas nas aulas de Educação Física, para muitos professores, implementar conteúdos relacionados as manifestações das lutas é deparar-se com inúmeros entraves relacionados à diversas questões, por vezes errôneas, tanto internas quanto externas. Outros inúmeros estudos, alertam sobre esses dilemas, como também trazem consigo sugestões de como transpor alguns desses obstáculos.

Del Vecchio e Franchini (2006), citados por Rufino e Darido (2015), vão além quando julgam que o impasse em desenvolver a unidade temática relativa as lutas na escola devem-se, em grande parte, a uma formação inicial fragilizada quanto a abordagem desse conteúdo, restringindo-se a apenas uma modalidade, ou às vezes nem mesmo se tem a presença desse conteúdo na grade curricular. Assim, o profissional que irá ministrar a disciplina de lutas no ensino superior é primordial nesse caminho, pois ele carrega consigo a incumbência de disseminar as questões críticas para o ensinamento desse conteúdo na escola, uma vez que é um dos encarregados por construir a formação do professor da educação básica. É indispensável que o professor do ensino superior estimule a apropriação do documento normativo em vigor, para que não haja prerrogativa se é possível ou não ensinar esse conteúdo, e sim o que e como ensinar esses conteúdos durante as aulas.

Especificamente as lutas são práticas importantes e que acompanham os seres humanos ao longo da vida e que se transformaram conforme as necessidades da sociedade em praticá-las (Rufino \& Darido, 2015). No sistema educacional, os Parâmetros Curriculares Nacionais-PCNs recomendam que as lutas e artes marciais podem ser exploradas nas aulas de Educação Física escolar, através de atividades lúdicas e também de forma competitiva (Brasil, 1997).

O conteúdo em questão inserido nos PCNs é definido como:

As lutas são disputas em que o (s) oponente (s) deve (m) ser subjugado (s), mediante técnicas e estratégias de desequilíbrio, contusão, imobilização ou exclusão de um determinado espaço na combinação de ações de ataque e defesa. Caracterizam-se por uma regulamentação específica, a fim de punir atitudes de violência e de deslealdade. Podem ser citados como exemplo de lutas desde as brincadeiras de cabo de guerra e braço de ferro até as práticas mais complexas da capoeira, do judô e do caratê (Brasil, 1997, p.32).

Um novo documento que substitui os PCNs é a Base Nacional Comum Curricular-BNCC, documento normativo que está em vigor, e tem como finalidade primária estabelecer o conjunto orgânico e progressivo dos conhecimentos essenciais que devem ser direcionados a todos os alunos ao longo de toda a Educação Básica, fundamentados nos conceitos éticos, políticos e estéticos que se destinam a formação humana integral e à edificação de uma comunidade justa. As lutas são contempladas na BNCC no segundo ciclo $\left(3^{\circ}, 4^{\circ}\right.$ e 5 anos) com o objetivo de desenvolver lutas do contexto comunitário e regional dos alunos e lutas de matriz indígena e africana, no terceiro ciclo $\left(6^{\circ}\right.$ e $7^{\circ}$ anos) o tema torna-se lutas do Brasil e no quarto ciclo $\left(8^{\circ}\right.$ e $9^{\circ}$ anos) tem como diretriz as lutas do mundo. Pertencente à BNCC, o conteúdo é definido como:

[...] focaliza as disputas corporais, nas quais os participantes empregam técnicas, táticas e estratégias específicas para imobilizar, desequilibrar, atingir ou excluir o oponente de um determinado espaço, combinando ações de ataque e 
defesa dirigidas ao corpo do adversário. Dessa forma, além das lutas presentes no contexto comunitário e regional, podem ser tratadas lutas brasileiras (capoeira, huka-huka, luta marajoara etc.), bem como lutas de diversos países do mundo (judô, aikido, jiu-jítsu, muay thai, boxe, chinese boxing, esgrima, kendo etc.) (Brasil, 2018, p. 218).

Todavia, a inexistência de apropriação do documento que norteia e normatiza os conhecimentos essenciais a que os alunos devem ter acesso e se apropriar durante todo o período da Educação Básica, geram, conforme Rufino e Darido (2015), inúmeras indefinições sobre quais conhecimentos relacionados às lutas devem ser de fato elegidos para as aulas de Educação Física na escola, e como elas devem compor o currículo proposto. Para que haja mudanças e transformações na ação no contexto escolar, é necessário, previamente, dialogar e debater sobre esse documento de âmbito nacional, oportunizando que uma visão crítica seja empregada em associação ao ensino das lutas, e o abismo existentes entre as aulas de Educação Física no país seja minimizado. Temos conhecimento da importância desse conteúdo na escola, devido a diversos fatores e suas contribuições, embora ainda faltem sugestões e recomendações de como abordar essas expressões na escola, indicando quais modalidades utilizar, quando ensiná-las e principalmente o que ensinar das lutas no decorrer da Educação Básica.

Desse modo, compreendemos que deve-se considerar, a formação do cidadão que vai se apoderar dos diferentes objetos de conhecimento, produzidos pela unidade temática lutas, a importância da escola vai além do conhecimentos de golpes, fundamentos, técnicas e táticas, como tampouco formar atletas e lutadores, o intuito primordial é que por meio das lutas os educandos se apropriem de novos valores e visões sobre esta temática. Além de se apresentarem como ferramentas que ao serem exploradas adequadamente pelos professores, podem representar um meio para o desenvolvimento de elementos necessários à formação dos alunos. Da mesma forma, se beneficiam das práticas esportivas para promover a paz, a união, o respeito por regras e adversários, buscando a partir disso, contribuir na edificação de um mundo melhor, certamente sem discriminação e procurando assegurar a prática esportiva como direito de todos.

\section{Metodologia}

Com o intuito de atingir os objetivos traçados, a metodologia utilizada caracterizou-se por uma investigação de campo com uma abordagem quanti- qualitativa, uma vez que segundo Souza e Kerbauy (2017, p. 37): “[...] a realidade é multifacetada e, como tal, não é superficial afirmar que dados gerados por métodos distintos podem ser agregados, na perspectiva de compreensão das várias faces da realidade".

O universo da pesquisa foi formado por oito $(n=6)$ professores que ministram aulas de Educação Física no ensino fundamental na rede pública de ensino do município de Fortaleza-Ceará. Foi aplicado um questionário on-line, através da Plataforma Google Forms e usando o aplicativo WhatsApp para encaminhar aos professores que trabalham com a disciplina de Educação Física no município de Fortaleza/Ce. Na oportunidade, foram explicados os objetivos da pesquisa e os procedimentos para a coleta dos dados, bem como a solicitação para a realização da pesquisa através do Termo de Consentimento Livre e Esclarecido (TCLE).

Importa destacar que os participantes tiveram sua identidade preservada, e foram identificados utilizando-se se os seguintes códigos para designar professor um, professor dois, sucessivamente, como se segue: P1, P2, P3, P4, P5, P6. A técnica escolhida para realizar a coleta de dados foi o questionário, que para Gerhardt e Silveira (2009, p. 69) "é um instrumento de coleta de dados constituído por uma série ordenada de perguntas que devem ser respondidas por escrito pelo informante, sem a presença do pesquisador".

Para análise dos dados foi realizado o método de conteúdo de Bardin (2011), cuja análise é realizada em três etapas que consiste em: 1) Pré-Análise: momento de preparação do material para deixá-lo pronto antes da aplicação da pesquisa; 2) Análise: "exploração do material"; é a organização das respostas e 3) Interpretação dos resultados obtidos: as informações coletadas são tratadas de modo significativo e válido. Utilizou- se ainda, o pacote estatístico SPSS (Statistic Package for Social 
Science) para a realização de uma análise estatística e descritiva dos dados. Estes foram organizados sinteticamente, de modo que se deu preferência ao uso de tabelas e gráficos para apresentação dos dados quantitativos.

A pesquisa respeita os aspectos éticos da Resolução 466/12, do Conselho Nacional de Saúde, que define as normas para pesquisa com seres humanos, considerando o respeito pela dignidade humana, à proteção dos princípios éticos aos participantes das pesquisas científicas (Brasil, 2012).

\section{Resultados e Discussão}

Com base na análise dos questionários foi possível organizar os dados em duas categorias temáticas, seguindo as referências pautadas na análise de conteúdo de Bardin (2011). Os depoimentos foram organizados em duas categorias elaboradas a partir das falas dos sujeitos da pesquisa: a) Formação em artes marciais, esportes de combate e lutas na graduação; e b) aplicação prática e conhecimento do tema lutas na Educação Física Escolar.

\section{Formação em Artes Marciais, Esportes de Combate e Lutas na Graduação}

Os docentes foram questionados a respeito da disciplina da formação inicial voltada para o ensino das lutas. Questionou-se quanto a presença dessa temática no currículo, assim como o que lembravam acerca dos conteúdos, quais modalidades foram abordadas e como se deram as avaliações.

Quanto a presença do ensino das lutas durante a graduação, $100 \%$ (6) dos docentes afirmaram sobre a existência do componente curricular lutas em sua formação inicial, como é possível observar no Gráfico 1:

Gráfico 1 - Ensino das lutas na formação inicial.

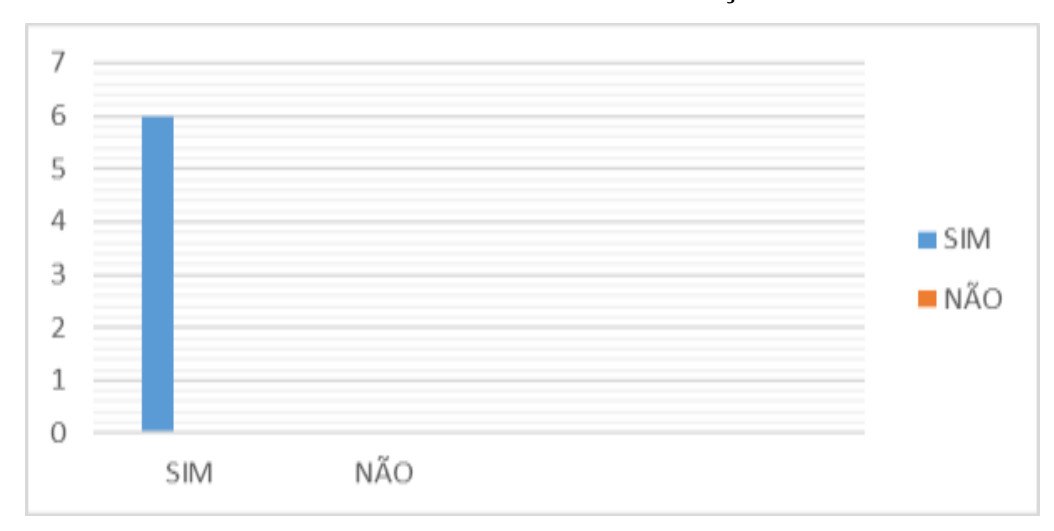

Fonte: Autores (2021).

Em relação à presença da disciplina voltada para o tema em questão, no histórico dos participantes dessa pesquisa, nota-se que um percentual de 33,3\% (2 dos 6 seis professores) optara por não cursar esta disciplina em sua formação inicial, e $66,7 \%$ (4) afirmam ter cursado a disciplina. Posto isso, acreditamos que não havia a obrigatoriedade desta disciplina ser cursada em alguns currículos, sendo optativa. 
Gráfico 2 - Periodicidade na disciplina de voltada para o tema em questão na formação inicial.

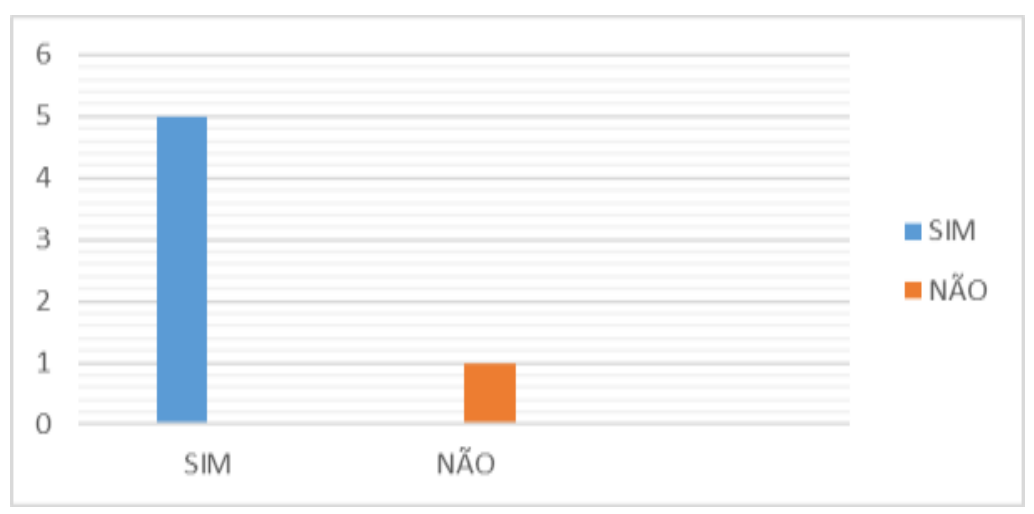

Fonte: Autores (2021).

Vale ressaltar que, de acordo com Rufino e Darido (2015), a resolução do Conselho Nacional de Educação / Câmara de Educação Superior $n^{\circ} 7$ de 31 de março de 2004, que institui as Diretrizes Curriculares Nacionais para os cursos de graduação em Educação Física, tem como objeto de estudo e cumprimento o movimento humano em suas inúmeras manifestações, tais como as lutas (Brasil,2004).

No entanto, uma crítica que sobrevém a essa resolução, implica em dizer que o ensino das lutas é estabelecido em termos de diretrizes curriculares, todavia mostra-se como disciplina optativa em algumas matrizes curriculares, não necessariamente efetiva no currículo obrigatório, à vista disso, tende a ser uma temática insuficientemente abordada por alguns cursos de formação superior na Educação Física, o que reverbera em problemas para sua concretização no âmbito escolar. Diante disso, Rufino e Darido (2015), ressaltam a importância de emergir as opiniões e entendimentos de professores que estão de modo direto envolvidos na formação de profissionais, visto que, o campo da Educação Física tem provido insuficientemente no que se concebe a formação em lutas no ensino superior, assim como em seu trato pedagógico na área da Educação Física Escolar.

Hegele et al. (2018) encontraram resultados divergentes quanto a presença do componente curricular lutas nos currículos das formações iniciais dos participantes de sua pesquisa, estes entendem que seria essencial como subsídio primordial para explorar essa temática em suas aulas. Esse achado é similar a outros estudos, uma vez que o principal argumento apontado pelos professores para não abordar o conteúdo lutas na Educação Física Escolar foi a sua formação inicial não contemplar este conteúdo.

Concordamos que a ausência desse componente curricular na formação inicial pode ser um fator restritivo na prática pedagógica do professor e consequentemente, um fator limitante na utilização das lutas como unidade temática nas aulas de Educação Física Escolar. Acerca disso, Rufino e Darido (2013) apontam que um dos maiores problemas da inserção deste conteúdo na Educação Física escolar, é que para os professores, desenvolver lutas como atividade nas escolas, os mesmos, devem ter alguma experiência extracurricular ou praticar alguma modalidade de luta e não é por esse lado que deve ser trabalhado já que a formação do professor capacita para que uma boa iniciação seja feita pelos mesmos. Assim, é que faz-se necessário uma formação que permita aos professores conhecimentos suficientes para desenvolver com o conteúdo a ser ensinado.

Neste interim, corroboramos com Corso e Antunes (2021) ao afirmarem que na formação inicial em Educação Física, o ensino de Lutas deve estar presente no intuito de capacitar o graduando a trabalhar com seus futuros alunos sobre: aspectos históricos e culturais do tema; prática de jogos/dinâmicas/tarefas que envolvam determinados movimentos, técnicas e características de Lutas; além de vivências com certas modalidades e o conhecimento dos mais variados tipos de Lutas. 
Dando prosseguimento, foi solicitado aos docentes que recapitulassem a constituição e estruturação da disciplina do tema em questão, como por exemplo; quais conteúdo, qua/is modalidades foram abordadas, como foram as avaliações. Seguem as narrativas:

Foram abordados especificamente o Karatê e o Judô. História, características e técnicas. Não recordo muito do processo avaliativo, mas, salvo engano, tivemos que apresentar o $1^{\circ}$ kata do Karatê. (P3)

Aulas de Karatê (catar); Capoeira e Judô - as duas últimas foram mediadas pelos alunos da disciplina. Era bem superficial enfatizando apenas na luta em que o professor era perito, no caso o Judô. (P5).

Na verdade, a disciplina aparece no meu histórico escolar como " Karatê e Judô" e não como lutas. A disciplina se resumiu em três meses de judô onde aprendemos alguns golpes de forma lúdica, e mais três meses de karatê que foi bem técnico e que a avaliação da disciplina se resumia a aprendizagem do kata heian shodan. (P6).

Concernente a esse resultado, Del Vecchio e Franchini (2010) mencionados por Rufino e Darido (2015) consideram que o inconveniente em desenvolver a temática lutas na escola ocorre, em parte, pela má formação profissional em Educação Física. Para esses autores, em inúmeras ocasiões os cursos de graduação revelam formações insuficientes em relação a estas práticas, ora restringindo o ensino a apenas uma ou duas modalidades, ora nem sequer havendo a presença destes conteúdos como disciplina obrigatória a ser cursada nos cursos de formação inicial, fato que impossibilita a presença dessa temática na escola, uma vez que pode restringir as intervenções profissionais dos professores de Educação Física.

Rufino (2016) exprime que, embora haja empecilhos ao se pensar as ações pedagógicas para a promoção do ensino das lutas tanto no ambiente escolar quanto em outros ambientes educacionais, nos resta pensar na superação de paradigmas, não somente com o intuito sobre o trato do conhecimento da temática lutas no contexto escolar, como também reflexões e debates sobre o tema em questão. Fica claro que existem dificuldades para a prática das lutas na escola, porém, empenhar-se sobre essas adversidades é relevante tendo em vista o desenvolvimento dessas práticas consolidadas em reflexões pedagógicas e científicas.

Sobre a oferta da disciplina voltada para o tema questão em formato optativo na formação inicial exibida no gráfico 3 , $33,3 \%$ (2 dos 6 seis docentes) afirmaram ter cursado a disciplina embora a proposta fosse voluntária, esse apontamento nos soa como um aspecto positivo, visto que vai de encontro a recomendação do documento normativo vigente que sugere o trato pedagógico das lutas em quase toda a educação básica. Esse dado nos revela ademais o compromisso desses profissionais em adentrar em um processo de apropriação relacionado às lutas durante sua formação acadêmica, contribuindo junto a proposta do referido documento normativo, que exprime a importância do profissional de Educação Física explorar as diversas temáticas referentes a Cultura Corporal de Movimento, propiciando ao aluno a vivência prática, a reflexão e ressignificação da unidade temática em várias situações de suas vidas, participando da sociedade de forma consciente e confiante. 
Gráfico 3 - Cursou alguma disciplina optativa ligada ou relacionada ao tema Artes Marciais, Esportes de Combate e Lutas?

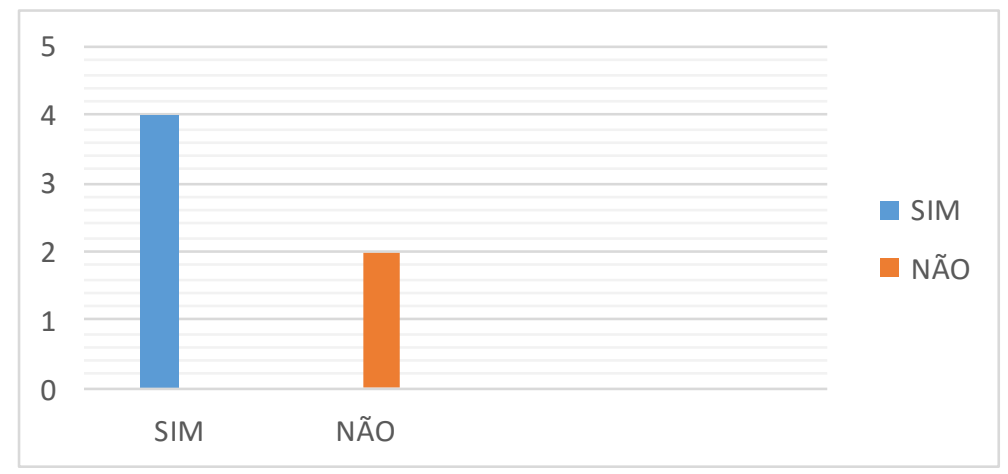

Fonte: Autores (2021).

Os docentes também foram questionados sobre a utilização da unidade temática lutas em suas aulas, como demonstra o gráfico 3. Em sua totalidade afirmaram aplicar o tema referido em suas aulas. Os resultados acerca da inserção das lutas por meio dos profissionais participantes da pesquisa corroboram com as diretrizes recomendadas pelos documentos orientador e normativo respectivamente; PCNs (Brasil, 1997), ambos orientam a inclusão das lutas, por sua contribuição social, relevância histórica e seu potencial educativo.

Esse dado revela, dentre outras coisas, a fragilidade na rede de ensino em proporcionar a qualificação de seu corpo docente. Nesse sentido, muitos elementos nos ajudam a compreender essa fragilidade, a saber: a pós-graduação ainda ser um espaço elitizado e de difícil acesso, o não incentivo das prefeituras, a negação na liberação de carga horária dos professores que conseguem aprovação, além do não reconhecimento salarial em seus planos de cargos e carreiras a partir dos títulos adquiridos.

Na proposta da BNCC, os conteúdos estão organizados em seis unidades temáticas: brincadeiras e jogos, danças, esportes, ginásticas (demonstração, condicionamento físico e conscientização corporal), lutas e práticas corporais de aventura. A unidade temática Lutas focaliza as disputas corporais, nas quais os participantes empregam técnicas, táticas e estratégias específicas para imobilizar, desequilibrar, atingir ou excluir o oponente de um determinado espaço, combinando ações de ataque e defesa dirigidas ao corpo do adversário. Dessa forma, além das lutas presentes no contexto comunitário e regional, podem ser tratadas lutas brasileiras e lutas de diversos países do mundo (Brasil, 2017). É preciso que o professor de Educação Física desmistifique a ideia de que para ensinar o conteúdo lutas seja necessário o domínio de alguma modalidade específica, como treinador ou praticante e conheça os princípios comuns entre as lutas e as diversas formas de ensiná-las nas escolas, para que propicie ao aluno a oportunidade de vivenciá-las e se apropriar dessa prática corporal (Ferreira et al, 2021).

Darido e Rangel (2005) apontam que conforme os princípios que deveriam ser considerados para inserir os alunos na Cultura Corporal de Movimento, devemos recorrer ao que se refere a diversidade para garantir a pluralidade de vivências corporais, assim como resgatar o conceito de cidadania como eixo norteador para a democratização do acesso à Educação Física em face das diversas manifestações da Cultura Corporal de Movimento. As mesmas autoras, agregam ao mencionar que, ao garantir que a Educação Física seja fundamentada na diversidade de conteúdo, possibilitamos que essas manifestações corporais sejam consideradas e propagadas, além de promover um saber democrático por intermédio da busca pela superação das desigualdades. 


\section{Aplicação Prática e Conhecimento do Tema Lutas na EFE}

Na segunda categoria, os professores foram questionados sobre a aplicação prática e conhecimento do tema Lutas na Educação Física escolar.

Gráfico 4 - Você utiliza ou utilizou o conteúdo de lutas em suas aulas de Educação Física Escolar?

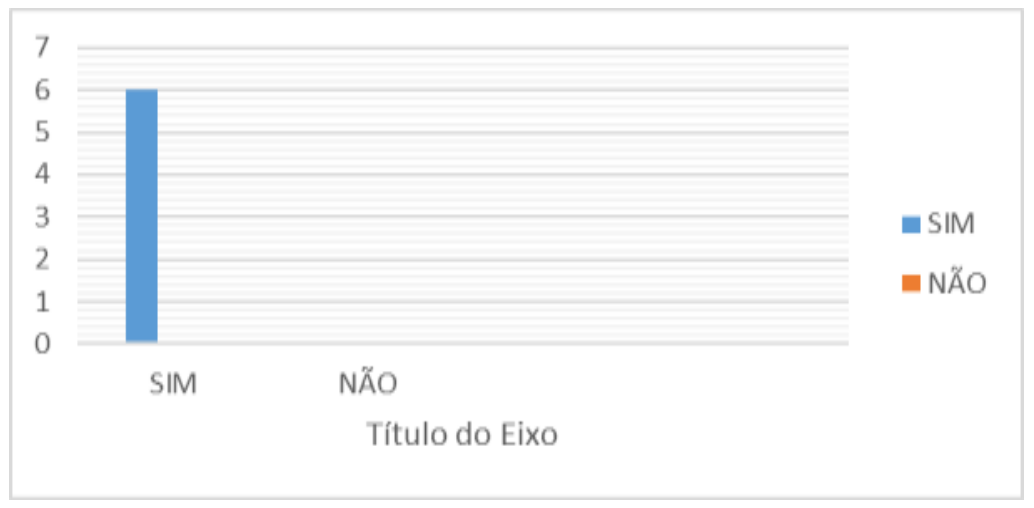

Fonte: Autores (2021).

Constatamos, com amparo nas respostas obtidas, que existe, expressa por todos os professores, a defesa da ideia de garantir a inclusão e a possibilidade de vivências para além dos esportes tradicionais, tais como as lutas, ampliando as chances de uma possível identificação.

Contrariamente, Berton (2018) descreve um cenário que vai em direção oposta ao que afirma o gráfico 4, quando diz que muitos profissionais ainda arriscam em currículos tradicionais por estar confortáveis na condição segura e protegida contra as incertezas e as indefinições do ato de conhecer. Vinculam a prática da Educação Física apenas a uma parcela da Cultura Corporal de Movimento, embora documentos recomendem outras inúmeras manifestações.

Desta feita, tratar da Educação Física somente a partir de currículos tradicionais, implicaria restringir a possibilidade de contribuição que as demais manifestações corporais podem proporcionar. Ressaltamos a importância dos professores de Educação Física se apropriarem dos referenciais teóricos que contribuem para fomentar a nossa área de atuação, tal como a BNCC (Brasil, 2017), que determina quais os conteúdos essenciais a que os alunos devem ter acesso durante toda a Educação Básica.

Rufino e Darido (2013) ressaltam que o professor só pode ensinar aquilo que conhece, que lhe é habitual, aquilo que ele compreende, mas, sobretudo, aquilo que ele acredita ser válido e legítimo a seus próprios ideais. Sem inteirar-se sobre o significado das lutas enquanto um fenômeno plural e abrangente, o seu ensino continuará sendo negado aos alunos, mesmo com a proposta do referente tema nas diretrizes curriculares dos estados e da posição de autores já citados nesse estudo, tais como Parâmetros Curriculares Nacionais (1997), Base Nacional Comum Curricular (2017), Ferreira (2006), Rufino e Darido (2015).

Quando indagados sobre como desenvolvem/desenvolveram a temática em suas aulas, as respostas obtidas foram diversas, os profissionais frequentemente se utilizam de mais de uma forma de apresentar as lutas em suas aulas (Gráfico 5). 
Gráfico 5 - Se a resposta da questão for positiva, como você desenvolve ou desenvolveu suas atividades?

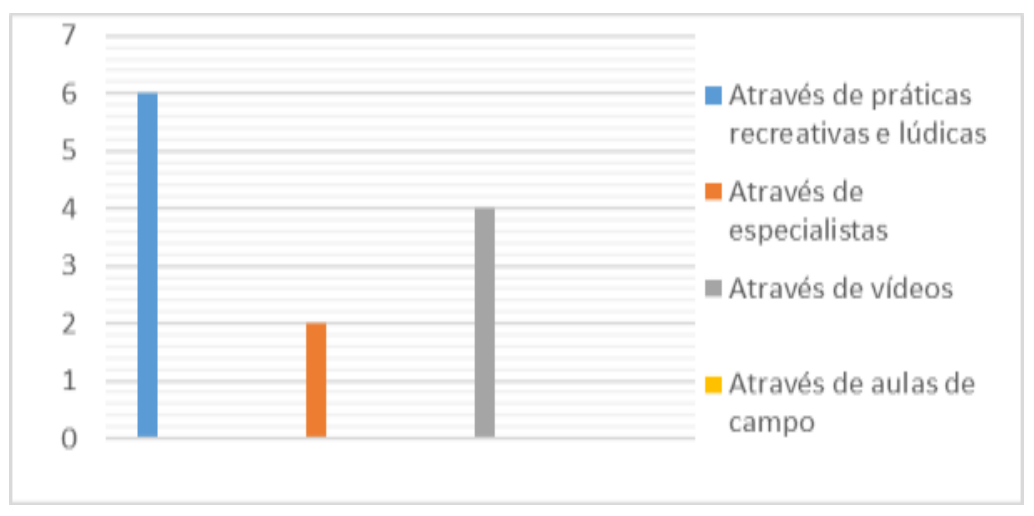

Fonte: Autores (2021).

Em relação ao desenvolvimento de suas atividades através de práticas recreativas e lúdicas todos os profissionais afirmaram fazer uso dessas possibilidades em suas aulas. Em referência ao auxílio de especialistas apenas 2 (dois) professores declararam ter solicitado esse suporte para o desdobramento de suas aulas, assim como 4 (quatro) profissionais citaram a contribuição de vídeos sobre a temática referida como subsídios relevantes para inclusão do tema nas aulas de Educação Física Escolar. Empregar-se de mais de uma forma de ensinar as lutas, amplia a visão sobre o ponto em questão. As aulas de Educação Física devem contemplar as lutas, tratar dessa temática nas aulas é necessário, mas também se faz imprescindível saber que lutas são estas e como serão ensinadas, quais modalidades e, seguramente o que são, e o porquê de serem ensinadas essas modalidades.

Para tanto os PCNs (Brasil,1997) ressalta a necessidade do esforço e da vontade do professor em estudar as lutas que irão ser exploradas na escola, bem como reconhecer que o método a ser empregado não pode ser igual àquele que antepõe a repetição de movimento, mas sim aquele que oportuniza a participação e o desenvolvimento das potencialidades de todos. Neste sentindo Lopes e Keer (2015), mencionam Betti (2011), argumentando que o professor deve fazer uso de diversas ferramentas para que os alunos obtenham conquistas e aprendizados nas atividades propostas. Especificamente na esfera educacional as lutas possuem um grande leque de possibilidades para oferecer aos alunos um desenvolvimento saudável, vinculado à compreensão da prática regular de atividade física, pois permitem o aprimoramento das relações sociais, o desenvolvimento do apreço às regras e a valores como cooperação, solidariedade e disciplina (Rodrigues \& Antunes, 2019).

Quando questionados sobre em qual etapa de ensino as lutas deveriam ser ministradas na rede municipal de Fortaleza, de forma geral os participantes afirmaram que em todas as etapas de incumbência do município era possível ministrar a temática lutas, embora em proporções distintas; $66,7 \%$ (4) dos docentes afirmaram que é possível explorar a temática lutas a partir da Educação Infantil, 83,3\% (5) declararam que ambas as etapas do ensino fundamental devem contemplar as lutas. Destaca-se que os participantes poderiam optar por mais de uma resposta. 
Gráfico 6 - Em sua opinião, a temática lutas deve ser ministrada em qual etapa de ensino ofertado pela rede municipal de Fortaleza?

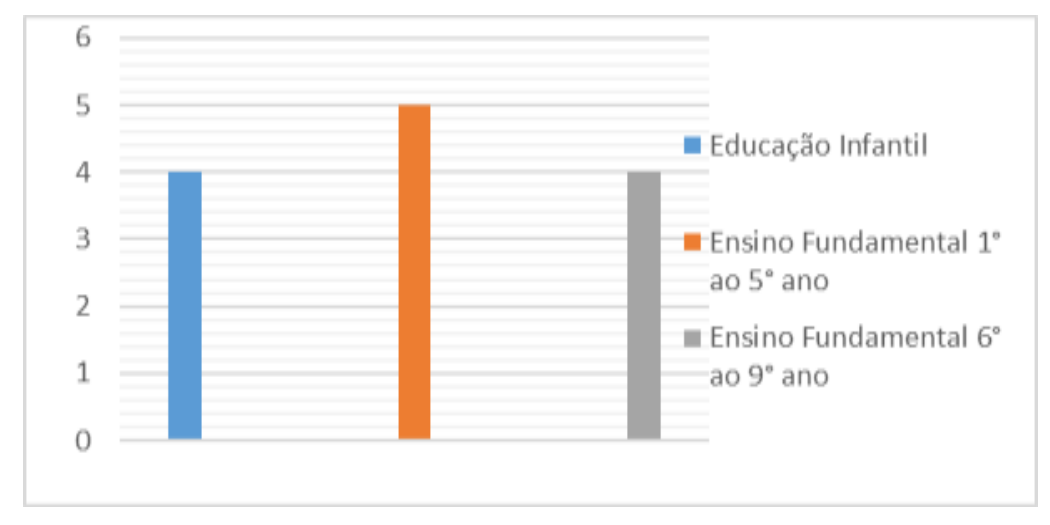

Fonte: Autores (2021).

Corroborando com o exposto acima, em um estudo realizado por Ferreira (2006), com o objetivo de compreender como os professores de Educação Física estava utilizando o bloco de conteúdos propostos nos PCNs (Brasil, 1997) no que se refere à prática das lutas, quando questionados sobre se era possível trabalhar as lutas na Educação Infantil: $76 \%$ (38 dos 50 professores) alegaram que não, que está deveria ser uma prática realizada em uma academia especializada e outros 24\% (12) afirmaram ser possível com o auxílio de especialistas ou de forma lúdica.

Embora o número de participantes da pesquisa citada seja superior ao deste estudo, ainda assim podemos traçar singularidades entre os resultados obtidos, visto que ainda nos deparamos com as divergências entre o ensino das lutas e a Educação Infantil.

Outro fator determinante na inclusão das lutas nas aulas de Educação Física escolar são os benefícios que o conteúdo pode trazer quando se diz respeito ao desenvolvimento do aluno, como aponta Ferreira (2006, p. 39-40):

"Esta prática pode trazer inúmeros benefícios ao usuário, destacandose o desenvolvimento motor, o cognitivo e o afetivo-social. No aspecto motor, observamos o desenvolvimento da lateralidade, o controle do tônus muscular, a melhora do equilíbrio e da coordenação global, o aprimoramento da ideia de tempo e espaço, bem como da noção de corpo. No aspecto cognitivo, as lutas favorecem a percepção, o raciocínio, a formulação de estratégias e a atenção. No que se refere ao aspecto afetivo e social, pode-se observar em alunos alguns aspectos importantes, como a reação a determinadas atitudes, a postura social, a socialização, a perseverança, o respeito e a determinação."

Diante do exposto no gráfico, podemos apontar algumas ressalvas relacionadas a inserção das lutas no ensino fundamental. Constatamos divergência entre as recomendações sugeridas pelos documentos oficiais curriculares; PCNs (Brasil, 1998), BNCC (Brasil,2017) e DCRC (2019) e as declarações dos participantes da pesquisa. É significativo rememorar que os documentos buscam apontar caminhos para diminuir o abismo que separa as aulas de Educação Física no Ceará e no país, de modo a assegurar que alunos e comunidade tenham um conhecimento maior sobre esse componente curricular. 
Gráfico 7 - Você acha que seus alunos podem se tornar mais agressivos ao praticarem lutas na Educação Física Escolar?

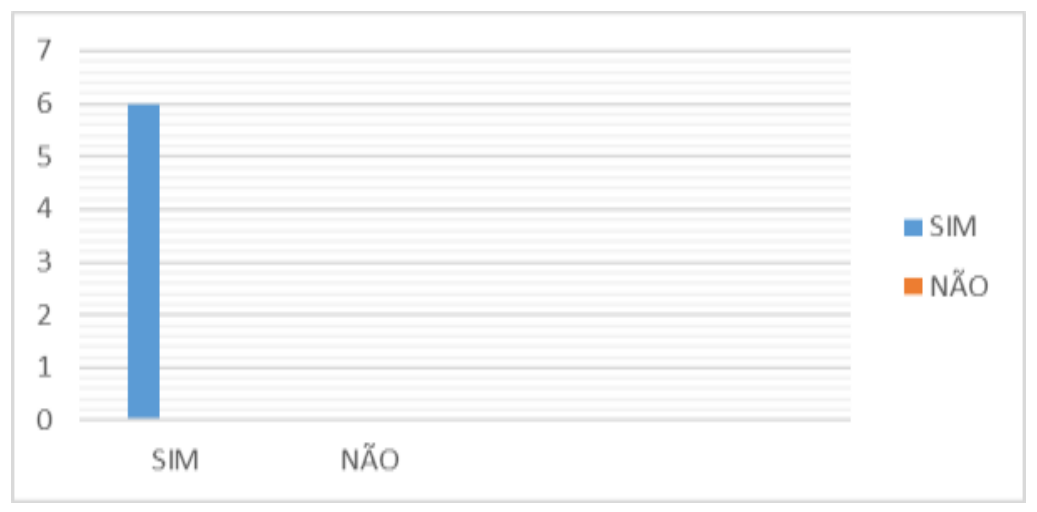

Fonte: Autores (2021).

Muitos estudos descrevem que a relação entre lutas e violência é uma característica enumerada como fator restritivo para o ensino da referida temática. Referente a agressividade, quando questionados no estudo de Ferreira (2006), 24\% dos participantes responderam que o ensino das lutas nas aulas de Educação Física Escolar pode desenvolver ou potencializar o comportamento agressivo dos alunos. $\mathrm{O}$ autor conclui que muitos desses profissionais possuem uma visão deturpada do que sejam as lutas, associando-as com violência e agressividade, atitude contrária à Educação Física e a própria filosofia das lutas.

O último item do questionário solicitou que os participantes justificassem o questionamento anterior, que tratava da relação agressividade e ensino das lutas nas aulas de Educação Física Escolar. Ao analisarmos as respostas dos participantes notamos que as respostas dos dois questionamentos convergiam entre si, ou seja, para os professores a agressividade não é promovida por meio do ensino das lutas na escola. Neste sentindo, emergiram duas categorias distintas, a primeira trata da agressividade oriunda de questões sociais. A segunda enfatiza a problematização a partir do conceito de lutas e brigas.

A primeira categoria se desenvolveu com base nas respostas a seguir, onde observamos que, para os participantes da pesquisa, a agressividade é fruto das relações sociais, da desigualdade e de múltiplas determinações sociais.

Agressividade vem do individual de cada um não sendo estimulado pela prática da luta (P1).

Acredito que a violência é uma questão social complexa que abrange a cultura do aluno e os significados que ele dá a certas questões. Assim, faz-se necessário essa problematização desde o início do trabalho com essa unidade temática, principalmente, enfocando a diferença entre briga e luta (P4).

O que torna as pessoas violentas e agressivas são suas experiências pessoais e a relação com o meio em que vivem (P5).

As respostas ao questionamento nos mostram que, na percepção inicial dos participantes com relação a agressividade, três, estabeleceu uma relação parcial de associação com as questões sociais ou até mesmo de outras práticas as quais os alunos possam estar inseridos. Houve uma forte consideração dos determinantes sociais como elementos que interferem na agressividade.

É relevante considerarmos, portanto, a agressividade como resultado de múltiplos fatores que inúmeras vezes tem suas raízes na desigualdade social, na falta de oportunidades e educação. Diante desse cenário, a escola surge como meio de promover a reflexão, bem como capacitar os alunos a conhecer e agir com responsabilidade diante de situações do cotidiano. É necessário que o ensino das lutas na escola se articule a valores para a promoção da formação de um cidadão, a fim de que os alunos se tornem sujeitos autônomos e críticos em relação a agressividade, comportamento este, constitucional e necessário 
para auto conservação e conservação da espécie, é uma forma de nos protegermos, de dar limites, é fundamental na sustentação de processos decisórios

Sobre a problematização a partir do conceito de lutas e brigas, observamos que os participantes julgam significativo o desenvolvimento das atividades a partir da definição de termos que transitam na inserção da referida temática. Sabemos que para muitos alunos e até mesmo para professores, pais e gestão, as lutas estão atreladas a práticas violentas e de desrespeito.

A respeito disso Segundo Souza Junior e Santos (2010), afirmam que como parte da cultura humana, as lutas representam um meio eficaz de educação e um conjunto de conteúdos altamente importante para a Educação Física escolar, pois, qualquer que seja a modalidade de luta, exige respeito às regras, a hierarquia e a disciplina, valorizando a preservação da saúde física e mental de seus praticantes. Esta relação das lutas com o respeito e a disciplina é apresentado na fala dos participantes como é possível observar a seguir:

\section{Lutas ensina respeito e disciplina que não combinam com violência (P2).}

Acredito que a violência é uma questão social complexa que abrange a cultura do aluno e os significados que ele dá a certas questões. Assim, faz-se necessário essa problematização desde o início do trabalho com essa unidade temática, principalmente, enfocando a diferença entre briga e luta (P4).

Antes de abordar o assunto de lutas faço uma introdução sobre a diferença entre briga e luta para que os alunos possam entender a diferença (P5).

A ação listada, de conceituar e diferenciar lutas de brigas, certamente é importante para o desenvolvimento do ensino das lutas no ambiente escolar, no entanto, não deve ocorrer de forma isolada. É necessário que os conceitos se articulem a outras propostas pedagógicas, levando em consideração o contexto social em que a escola está inserida, afim de que os alunos se tornem sujeitos autônomos e críticos em relação ao ensino das lutas.

Desta feita, compreendemos que não há incentivo à violência quando se pensa em trabalhar as lutas nas escolas, haja vista as inúmeras capacidades sociais, culturais e cognitivas, bem como muitos valores, que são desenvolvidos através dos esportes de combate. As lutas desenvolvem capacidades físicas importantes nos alunos, assim como as principais capacidades motoras essências para seu desenvolvimento saudável, como lateralidade, noção corporal, espacial e temporal, coordenação geral, flexibilidade e outros benefícios. Capacidades cognitivas também são desenvolvidas como raciocínio, atenção e percepção. Além do quesito social e afetivo que estimulam a socialização, trabalho em equipe e formação de opinião (Oliveira, 2019).

Portanto, refletir sobre o contexto onde o nosso aluno está inserido se faz essencial para a construção dos planejamentos de nossas aulas, buscando respeitar as características de cada comunidade, estando em conformidade com o projeto político pedagógico da escola, ampliando assim as possibilidades formativas e educacionais, considerando a diversidade cultural presente até mesmo em único município, garantindo dessa forma que os alunos possam vivenciar, discutir e se apropriar das práticas corporais. De maneira geral, o questionário diagnosticou, na maioria dos participantes, uma percepção ampla envolvendo está temática, que inicia no seu entendimento durante a formação inicial. Esse entendimento reflete em sua prática nas aulas de Educação Física.

\section{Considerações Finais}

No contexto da Educação Física escolar mais atual, a inserção das lutas ganharam diversos olhares e novas perspectivas que são, cada vez mais, fundamentais para que se possam melhorar as práticas pedagógicas dos professores no cenário escolar, especialmente a partir das orientações presentes nos parâmetros curriculares nacionais, que reconhecem e 
estabelecem as lutas como um dos pilares da Educação Física escolar, e mais recentemente com a promulgação da Base Nacional Comum Curricular. Entretanto, O questionário nos revelou uma aproximação limitada dos participantes acerca da unidade temática lutas na formação inicial, devido a sua ausência nas matrizes curriculares ou por sua abordagem insuficiente, por exemplo.

Em relação a inserção das lutas nas aulas de Educação Física, apontamos como positivo a declaração de que todos os participantes desenvolveram ou desenvolvem a unidade temática lutas em suas aulas. Quanto a forma de como essas atividades eram desenvolvidas, percebemos a utilização de jogos e atividades lúdicas como ferramentas facilitadoras unanimes nesse processo, como também a necessidade da busca por recursos externos ou ajuda de especialistas, visto que a maioria apresentou uma formação inicial insatisfatória em relação a referida temática. Com relação às lutas e as etapas de ensino, percebemos que para os participantes ainda existe a ideia de que está unidade temática não é viável a todos os níveis.

Portanto, esses dados contribuem para novas reflexões acerca da importância da Educação Física na formação e desenvolvimento de um cidadão crítico, autônomo e protagonista por meio de um trabalho planejado, inclusivo, democrático e integral, ampliando as possibilidades formativas, garantido o direito dos alunos de vivenciar, discutir e se apropriar das práticas corporais mais diversas. Portanto, propõe-se, que os professores que lecionam na educação básica busquem realizar leituras e estudos que envolvam a inserção das lutas nas aulas de Educação Física escolar, tendo em vista atribuir um maior significado à essa manifestação cultural produzida e transformada com o desenvolvimento da humanidade.

\section{Agradecimentos}

Agradecemos ao Grupo de Estudos e Pesquisas em Educação Física Escolar, da Universidade Estadual do Ceará, na qual todos os autores são membros, e que tem como coordenador o autor Heraldo Simões Ferreira.

\section{Referências}

Bardin, L. (2011). Análise de Conteúdo. Edições 70.

Berton, D. (2018). Manual do professor para Educação Física. Terra Sul.

Brasil. (1996). Lei de Diretrizes e Bases da Educação Nacional - LDB Lei no 9394/96.

Brasil. (1997). Secretaria de Educação Fundamental. Parâmetros Curriculares Nacionais: Educação Física. Brasília: Secretaria de Educação Fundamental, $\mathrm{MEC} / \mathrm{SEF}$.

Brasil. (2017). Ministério da Educação. Base Nacional Comum Curricular (BNCC). Brasília, MEC/CONSED/UNDIME. Disponível em: http://basenacionalcomum.mec.gov.br/images/BNCC_publicacao.pdf.

Brasil. (2004). Ministério da Educação. Conselho Nacional de Educação. Resolução no 7, de 31 de março de 2004. Institui as Diretrizes Curriculares Nacionais para os cursos de graduação em Educação Física, em nível superior de graduação plena. Diário Oficial da União, Brasília, DF, 05 abr.

Corso, J. S., \& Antunes, F. R. (2021). O ensino das lutas na Educação Física escolar: uma breve reflexão. Revista Saúde Viva Multidisciplinar da AJES, 4(5), 27-33.

Darido, S.C., \& Rangel, I.C.A. (2003). Educação Física na escola. Guanabara Koogan.

Darido, S.C., \& Souza Júnior, O. M. (2007). Para ensinar Educação Física: possibilidades de intervenção na escola. Campinas: Papirus.

Ferreira, H. S. (2006). As lutas na educação física escolar. Revista de Educação Física. 75(135), 23 - 45.

Ferreira, H. S. (2012). Ensino de Lutas na Escola. Peter Rohl.

Ferreira, H. S. (org). (2015). Educação Física Escolar: possibilidades metodológicas. Eduece.

Ferreira, N. R., Costa, J. L., Hudson, T. A., \& Meireles, J. F. F. (2021). Inserção das lutas na educação física escolar da cidade de Muriaé-MG. Revista Pensar a Prática, 24. https://doi.org/10.5216/rpp.v24.67744

Gerhardt, T. E; Silveira, D. T. (2019). Métodos de Pesquisa. Ufrgs, 2009. 120 p.

Gondra, J.G.; Schueler, A. (2008). Educação, poder e sociedade no império brasileiro. Cortez. 
Research, Society and Development, v. 11, n. 1, e43511125212, 2022

(CC BY 4.0) | ISSN 2525-3409 | DOI: http://dx.doi.org/10.33448/rsd-v11i1.25212

Hegele, B., González, F. J. \& Borges, R. M. (2018). Possibilidades do ensino das lutas: uma pesquisa - ação com professores de educação física. Caderno de Educação Física e Esporte, Marechal Cândido Rondon. 16(1), 99-107.

Lopes, R. G. B., \& Kerr, T. O. (2015). O ensino das Lutas na Educação Física Escolar: uma experiência no ensino fundamental. Revista Motrivivência, Santa Catarina. 27(45), 262-279.

Lopes, J. C., Bueno, C. A. M., Fiorini, M. L. S., \& Martínez-Ávila, D. (2019). Lutas na educação física escolar: metodologia através dos parâmetros curriculares nacionais - PCNs. Revista Brasileira de Educação Física e Esporte. 33(3), 401- 412.

Mazini Filho, M. L., Simões, M. R., Venturini, G. R. d. O., Savóia, R. P., Mattos, D. G., Aidar, F. J., \& Costa, S. P. (2014). O ensino das lutas nas aulas de Educação Física Escolar. Cinergis, 15(4), 176-181.

Nóbrega-Therrien, S. M. \& Therrien, J. (2004). Os trabalhos científicos e o Estado da questão: reflexões teórico-metodológicas. Estudos em Avaliação Educacional. 15(30), 5-16.

Oliveira, C. (2019). A importância das lutas na educação física escolar para formação integral dos alunos. Revista Científica Multidisciplinar Núcleo do Conhecimento. 6, 37-47.

Rodrigues, A. I. C., \& Antunes, M. M. (2019). Ensinando lutas na escola: percepções e expectativas de dirigentes do ensino fundamental. Revista Valore, Volta Redonda. 4(1), 885- 899.

Rufino, L. G. B., \& Darido, S. C. (2011). A separação dos conteúdos das "lutas" dos “esportes" na educação física escolar: necessidade ou tradição? Pensar a Prática. 14(3),1-17.

Rufino, L. G. B., \& Darido, S. C. (2013). Possíveis diálogos entre a Educação Física Escolar e o conteúdo Lutas na perspectiva da cultura corporal. Conexões: revista da Faculdade de Educação Física da UNICAMP, 11(1), 145-170.

Rufino, L. G. B., \& Darido, S. C. (2015). O ensino das lutas nas aulas de educação física: análise da prática pedagógica à luz de especialistas. Revista Educação Física/UEM. 26(4), 505-518.

Sampaio, J. C. S. (2017). A contribuição das lutas na Educação Física Escolar para a diminuição do bullying: considerações iniciais. 2017. f. 31 Trabalho de Conclusão de Curso (graduação) - Universidade Federal do Ceará, Instituto de Educação Física e Esportes, Curso de Educação Física, Fortaleza. http://www.repositorio.ufc.br/handle/riufc/36249.

Souza Júnior, T. P., \& Santos, S. L. C. (2020). Jogos de oposição: nova metodologia de ensino dos esportes de combate. EFDeportes.com, Revista Digital. Buenos Aires, 14(141).

Souza, K. R., \& Kerbauy, M. T. M. (2017). Abordagem quanti-qualitativa: superação da dicotomia quantitativa-qualitativa na pesquisa em educação. Educação e Filosofia. 31(61), 21-44. 